\title{
Regional entrepreneurial ecosystems: how family firm embeddedness triggers ecosystem development
}

\author{
Bernhard Fabian Bichler $^{1}$ (D) Andreas Kallmuenzer ${ }^{2}$ (D) Mike Peters $^{1}$ (D) \\ Tanja Petry ${ }^{1}\left[{ }^{10} \cdot\right.$ Thomas Clauss $^{3}$ (1)
}

Received: 14 April 2020 / Accepted: 29 December 2020 / Published online: 18 January 2021

(c) The Author(s) 2021

\begin{abstract}
Regional business development is driven by family firms, which are generally deeply embedded in their region, particularly in rural areas. This study explores how family entrepreneurs' embeddedness drives an entrepreneurial ecosystem as a regional context for innovation. For this purpose, the study brings together entrepreneurship research on embeddedness and on ecosystems, and develops the entrepreneurial ecosystem embeddedness framework to better understand the connection of entrepreneurs to their local environment along three dimensions. Analyzing qualitative interviews from the hospitality context with a pattern matching approach, we highlight the role of family entrepreneurs' (1) horizontal embeddedness in the economic and socio-political environment, their (2) vertical embeddedness in industry regimes, in particular the family, and their (3) spatial embeddedness in the region for value creation. Thereby we contribute to a differentiated understanding of how embeddedness as a social fabric relates to entrepreneurial ecosystems. The propositions of this study recommend raising awareness for managing entrepreneurs' embeddedness along these three dimensions since unilateral engagement and a lack of coordinated embeddedness can restrict value creation.
\end{abstract}

Keywords Entrepreneurial ecosystem $\cdot$ Embeddedness $\cdot$ Entrepreneurship $\cdot$ Family firms · Innovation · Rural

Mathematical Subject Classification 00-XX

Bernhard Fabian Bichler

bernhard.bichler@uibk.ac.at

Extended author information available on the last page of the article 


\section{Introduction}

Entrepreneurial ecosystem (EE) research has gained attention in the past years. This perspective complements entrepreneurship research by offering a systemic lens to "incorporate cultural, economic, social, and political considerations in an evolutionary view of how entities interact in society" (Ratten 2020, p. 1). EEs are defined as "a set of interdependent actors and factors coordinated in such a way that they enable productive entrepreneurship in a particular territory" (Stam and Spigel 2017, p. 407). EE research aims to better understand entrepreneurship within this spatial, temporal and social setting (Alvedalen and Boschma 2017; Brown and Mason 2017). Empirical scholarly work showed that EEs can substantially stimulate various aspects of a start-up process such as opportunity recognition and assessment, business planning and financing of the new venture (Audretsch et al. 2019; Nicotra et al. 2018). EEs are seen as a primary reason for the regional agglomeration of start-up firms in entrepreneurial hubs around the world (e.g., Berlin, Tehran, San Francisco, Malmö etc.). EEs have become popular also among practitioners and policymakers on the regional level because they elevate the relevance of a like-minded and supportive local environment for both outstanding entrepreneurship and regional development (Prencipe et al. 2020). While early research (Feld 2012; Isenberg 2010) was inspired by high-tech and start-up ecosystems in the United States and Israel, more recently scholars also considered regional EEs to explain entrepreneurial success in other contexts and regions (Cohen 2006; de Villiers Scheepers et al. 2018; Eichelberger et al. 2020). Previous EE research focused on the structural aspects of EE and the existence of certain actors (i.e., universities, venture capital firms, etc.) as well as the governance that facilitates the orchestration of EEs (Cunningham et al. 2019; Lingens et al. 2020). However, entrepreneurship in EE is about opportunity recognition by individuals to generate value (Cohen 2006; Stam and van de Ven 2019) and thus, ecosystems are first and foremost "complex social constructs" (Neumeyer et al. 2019, p.462) of interacting and independent entrepreneurs who are involved in mutual relationships and are in constant exchange with their environment (Stam 2015). Therefore, understanding EEs depends on acknowledging their context factors such as the nature of interactions among the key actors (Brown and Mason 2017; Lingens et al. 2020).

Linking the myriad of entrepreneurship, family firm and embeddedness literature on the individual level in a coherent framework is still in an infant stage. However, its relevance is underlined by entrepreneurship studies that emphasize the spatial context, community dynamics (Roundy 2019) and embeddedness for family firms (Baù et al. 2019; Kallmuenzer and Peters 2017). Embeddedness refers to the diverse relationships within and across industry boundaries that allow entrepreneurs to create value (Weiler and Hinz 2019). In this sense, embeddedness represents a vital concept to better explain the dynamic nature that shapes entrepreneurial activity (Dahl and Sorenson 2012; Jack and Anderson 2002). We believe that embeddedness defined as the nature, depth, and extent of an individual's ties into the environment (Jack and Anderson 2002) serves as a social fabric that contextualizes the dynamic 
interplay between entrepreneurship, family firm and embeddedness in regional EE literature in important ways. Within this social fabric elements of the entrepreneurial ecosystem such as institutions, knowledge and networks may be interwoven and thus connected to enable value creation. Following Thompson et al. (2018) we contribute to this important perspective of EE research by investigating the role of embeddedness as a social fabric in (1) socio-political and economic environments, (2) family regimes and (3) spatial systems.

In particular, we address how embeddedness as a regional context for innovation supports or prevents family entrepreneurs from creating and maintaining a productive EE in rural areas, in which family firms' ties with the environment have traditionally been strong. This is particular the case for H\&T firms and their often multigenerational involvement in promoting the region to visitors for income provision and thus, we consider prominent peculiarities from these industries such as their particularly strong spatial and social embeddedness, which has grown by doing business over various generations (Kallmuenzer and Peters 2017). As a result, family firms in our study are characterized by their high-involvement and long-term commitment, which aligns with previous studies showing that family firms are a unit of analysis that is fundamentally different from non-family firms (Gómez-Mejía et al. 2007; Le Breton-Miller and Miller 2016). These characteristics, together with often perceived responsibility for a region and non-aggressive behavior towards local competitors, are commonly associated with social embeddedness of family entrepreneurs (Kallmuenzer and Peters 2018).

Studying family firms active in H\&T within a regional EE is promising since the ecosystem perspective proposes a two-way relationship with entrepreneurship as an outcome but also a resource (Bachinger et al. 2020). Family firms have the potential to exercise "both input and output roles in entrepreneurial ecosystems" as highlighted by the Entrepreneurship Ecosystem Research Network (MacKenzie 2016). Thus, existing family firms can provide guidance and support to new ventures but can also capitalize on the sum of services provided in the ecosystem, e.g., existence of formal institutions or established demand (Stam 2015). More specifically, we assume that the role of family firms in EEs is of particular importance as (1) family firms are characterized by intense and often personal relationships with their stakeholders (Gamble et al. 2020), (2) considerations about sustainability as well as welfare in the society typically play an important role for family businesses (Kallmuenzer et al. 2017), and (3) family businesses have unique characteristics regarding entrepreneurship as they are usually quite agile but also risk-averse at the same time (Duran et al. 2016). Thus, we pose the question, "how does the family entrepreneurs' individual embeddedness drive the emergence of a regional EE?." This aims to better understand the hidden, interpersonal foundations of EE. This is important since understanding patterns of embeddedness of family entrepreneurs in EEs enables fostering and implementing innovations, which has become highly important due to disruptive change and increased competition (Bouncken et al. 2019; Clauss et al. 2020).

Empirically, as we want to explore this new yet not established field, our study draws on a qualitative research design (Creswell 2009) with semi-structured interviews. We rely on a set of 20 hospitality family entrepreneurs, who have been 
previously shown to be relevant actors for investigating EE (Flores et al. 2017; Kline et al. 2014; Pechlaner et al. 2018). Conceptually, we draw on previous embeddedness work (Granovetter 1973; Gulati 1998; Uzzi 1997) and integrate embeddedness into a three dimensional framework. This helps to better understand the underlying processes of entrepreneurial activity, especially in the context of regional EEs (de Villiers Scheepers et al. 2018; Prencipe et al. 2020; Villegas-Mateos 2020). Our research contributes to the theoretical foundations of EE research by specifying the relational dimensions between the individual level of family entrepreneurs and their environment into horizontal, vertical and spatial embeddedness. We illustrate the importance of horizontal embeddedness in economic and socio-political environments, vertical embeddedness in industry regimes, and spatial embeddedness in the ecosystem. While horizontal embeddedness refers to the importance of local ties and relationships for entrepreneurial activity, vertical embeddedness explores family entrepreneurs' involvement in the business regime and the family system. Finally, spatial embeddedness refers to different degrees of expansion, ranging from local networks to global EE, which can benefit firm performance.

\section{Theoretical background}

Concepts of EE supplement entrepreneurship research by providing a systemic framework for established theories (Ferreira et al. 2019). Despite the pending consolidation in terms of definitions and frameworks (Kang et al. 2019; Spigel and Harrison 2018; Stam 2015), two major research streams can be distinguished in the literature. The first stream provides an actor-centric view of entrepreneurship (Stam 2015), which focuses on social systems, configurations, and networks as a focal point of entrepreneurship (Theodoraki et al. 2018). Thereby, actor-centric approaches concentrate on social interactions and the importance of entrepreneurial agents for value creation (Cohen 2006). The second stream emphasizes the importance of processes, which need to be aligned to deliver a particular value proposition. This ecosystem approach, also called ecosystem-as-structure, "starts with a value proposition and seeks to identify the set of actors that need to interact in order for the proposition to come about" (Adner 2017, p. 41). Both streams highlight that entrepreneurship in ecosystems is dependent and enabled by a set of conditions such as the interdependence of actors and tie configurations, diversity and density as proxies of embeddedness (Stangler and Bell-Masterson 2015), which allows entrepreneurial activity (Stam 2015). However, the actor-centric approach is particularly suitable to grasp the pecularities of the H\&T industry in regional EEs since it focuses on "communities of associated actors defined by their networks and platform affiliations" (Adner 2017 , p. 40), which also aligns with the important role of family firm entrepreneurs in H\&T (Kallmuenzer et al. 2018).

In the family-driven $\mathrm{H} \& \mathrm{~T}$ industry EEs represent a new and yet not established research field (Bachinger et al. 2020; Eichelberger et al. 2020; Milwood and Maxwell 2020). As a result adapted approaches of measuring EE outcomes next to density, fluidity and connectivity (Stangler and Bell-Masterson 2015) are needed to account for regional EEs. This is also supported by H\&T scholars stating that 
"[tourism] destinations [represent] local innovation systems in which public and private actors generate a co-evolutionary process of innovation that is dynamically influenced by the spatial dimension" (Trunfio and Campana 2019, p.1). Furthermore, destinations are often discussed as networks of actors: Strobl and Peters (2013) discuss the entrepreneurial linkages, others interpreted destinations as entrepreneurial networks (Boesen et al. 2017) or systemic leadership networks (Zehrer et al. 2014). Since entrepreneurship in hospitality and tourism is particularly focused on opportunity-seeking within a defined geographical space (Ateljevic and Doorne 2000), we use the lens of Stam and Spigel stressing the need for coordination among interdependent actors to develop a regional cluster of productive entrepreneurship (Stam and Spigel 2017). This also accounts for the particular emphasis of previous EE research to understand ecosystems as social constructs (Neumeyer et al. 2019), where the spatial factor is a decisive force (Stam 2015; Stam and Spigel 2017). This spatial connotation of $\mathrm{EE}$, proposing that wealth and entrepreneurial success are fueled by local conditions and resources, distinguishes itself from nongeographical and conceptually distinct notions of business ecosystems which show a stronger focus on global competition and synergies (Hakala et al. 2020). Additionally, EE are often orchestrated by leading actors and thus differ from alliances requiring hierachical management especially in times of uncertainty (Lingens et al. 2020).

\subsection{Regional entrepreneurial ecosystems}

Previous research showed that entrepreneurial activity is strongly influenced by the spatial context (Korsgaard et al. 2015). Recent EE research underlined the need for a better understanding of how entrepreneurs' environment affects their entrepreneurial activities (Kang et al. 2019; Stam 2015). Among existing work of EE (for examples of EE frameworks see Spigel and Harrison 2018 and Stam 2015), the regional EE model of de Villiers Scheepers et al. (2018) highlights three subsystems, which enable value creation in a regional EE. Table 1 illustrates these three subsystems and highlights the responsible actors and necessary support-resources based on the H\&T industry.

The knowledge exploitation subsystem focuses on entrepreneurs, delivering products or services to customers, where they act as central (Stam 2015) but also evolving actors (Boesen et al. 2017; Strobl 2014; Strobl and Kronenberg 2016). The knowledge generation subsystem includes support systems such as universities, training programs (Prencipe et al. 2020) and H\&T industry-specific co-creation characteristics (Higuchi and Yamanaka 2017; Thees et al. 2020). The socio-political subsystem features intermediaries and government bodies, including destination management organizations (DMO) and helping to facilitate entrepreneurial activities (Baggio 2011; Beritelli et al. 2014).

The regional EE can also be related to Stam (2015), differentiating between framework (formal institutions, culture, physical infrastructure, and demand) and systemic (networks, leadership, finance, talent, knowledge, and support services/ intermediaries) conditions. In this context, Cohen (2006) explored how formal 


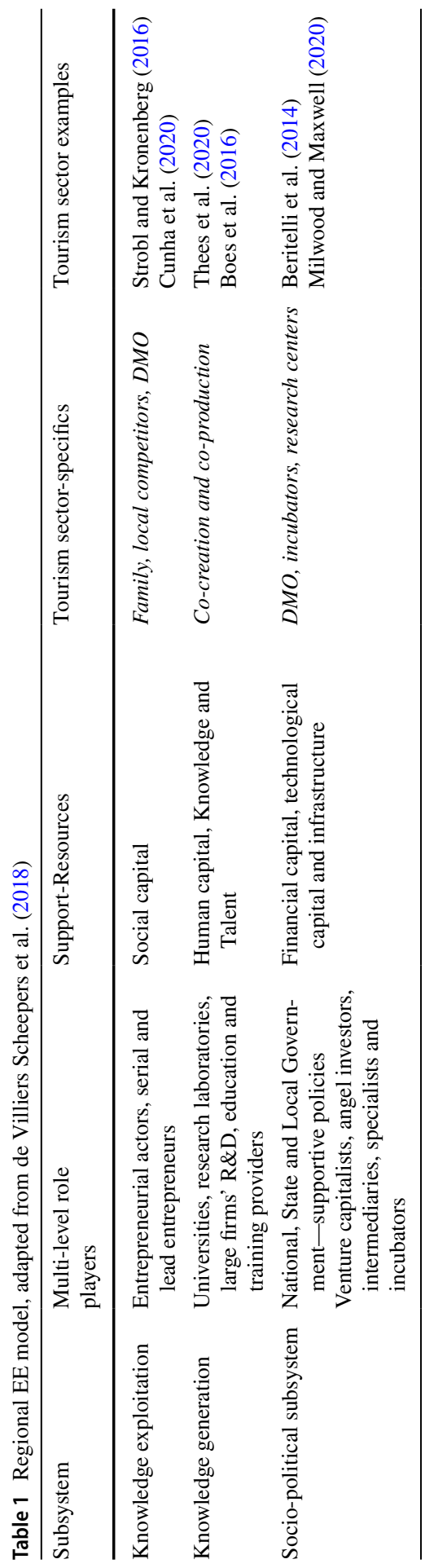


and informal networks, physical infrastructure, and culture contribute to innovative entrepreneurial activities within communities. Recently, Prencipe et al. (2020) showed that innovative spin-offs from universities are strongly influenced by the regional context, which also supports Krueger (2012), who highlights the complex dynamics between regional stakeholders. Motoyama et al. (2014) emphasized the generation of regional benefits through local entrepreneurs acting as role models and increasing tie-strength in local networks.

Family businesses often represent these local entrepreneurs and are essential for regional EE since those family entrepreneurs and their family members develop and possess intense social ties, leading to the formation of distinct entrepreneurial networks (Kallmuenzer and Peters 2018). This network is strongly influenced by the spatial and social context of entrepreneurship and motivates family firms to show awareness for social and environmental concerns and long-term orientation (Kallmuenzer et al. 2017). These dynamics find explanatory power in concepts such as socio-emotional wealth (Berrone et al. 2012), which displays how family firms balance between business, socio-environmental and family matters (Berrone et al. 2012; Gómez-Mejía et al. 2007). Following the family firm definition of Astrachan and Shanker (2003) and the commonly used requirement that ownership and management must be aligned in one or more families (Miller and Le Breton-Miller 2006), we consider a business a family business when at least two members of a family are active. Previous research emphasizes that family firms dedicate to social and environmental outcomes and their overall responsibility towards the environment (Kallmuenzer et al. 2017). In addition, recent work indicated how family firms contribute and benefit from regional EE (MacKenzie 2016). Summarizing, the role of embeddedness, local networks, family structures and the industry environment emerge as essential themes for regional EE.

\subsection{The role of embeddedness for entrepreneurial ecosystems}

Embeddedness is of particular importance for family entrepreneurs in serviceintensive industries such as the H\&T industry (Getz and Carlsen 2005; Kallmuenzer and Peters 2018). This industry is characterized by a high dependence and interrelationships between service providers who have to exchange services in order to deliver the final tourism product (Pikkemaat et al. 2019). The roots of embeddedness relate to the work of Granovetter (1973), highlighting the role of embeddedness on an organization level. The works of Gulati (1998) on relational and structural embeddedness in networks and Uzzi (1997) focusing on the role of arms-length and embedded ties, demonstrated that the embeddedness concept helps to study entrepreneurs as individual entrepreneurial agents, affected by social (Jack and Anderson 2002; Uzzi 1997) and spatial dynamics (Baù et al. 2019; Roundy 2019). Gulati (1998) refers to relational embeddedness as "direct cohesive ties as a mechanism for gaining fine-grained information" and to structural embeddedness as networks "beyond the immediate ties of firms and emphasize the informational value of the structural position these partners occupy in the network" (Gulati 1998, p. 296). 
Most recently, Lingens et al. (2020) showed that multilateral structures are benefitial for delivering joint value propositions in ecosystems but also pointing to the role of uncertainty "limit(ing) the size and the degree of multilaterality of ecosystem structure" (Lingens et al. 2020, p. 46). Combining the embeddedness perspective with the EE framework (de Villiers Scheepers et al. 2018; Stam 2015) offers novel insights on how entrepreneurs create, manage and sustain the complex social construct known as regional EE (Bachinger et al. 2020; Neumeyer et al. 2019).

Furthermore, also recent conceptual work on embeddedness from evolutionary economics provides an interesting perspective by introducing the triple embeddedness framework (Geels 2014). This perspective (Fig. 1) helps to understand that firms in regional EEs are embedded within different systems and subsystems of embeddedness. The understanding of horizontal embeddedness (Hess 2004) refers to linkages within the micro-level, including interactions between firms within the industry and the socio-political environment such as the local community and village (Roundy 2019). In contrast, vertical embeddedness refers to social structures such as rules and resources (Geels 2014; Hess 2004), which also includes relations between firms and industry regimes.

In the H\&T context, recent literature indicated the benefits of managing and leveraging interdependencies between tourism actors (Milwood and Maxwell 2020; Strobl and Kronenberg 2016). A plethora of studies assessed the role of networks (Baggio and Cooper 2010; Strobl and Peters 2013), clusters and interactions (Hjalager 2010). Recently, Narduzzo and Volo (2018) concluded in the innovation context that more research is necessary to explore how interdependent relations generate innovation "beyond dyadic interdependence" (p. 737). In this context, embeddedness conceptualizes social and economic activities as dependent and argues that integration into local structures matters for entrepreneurs (Baù et al. 2019; Rutten and Boekema 2007). Social embeddedness is an important

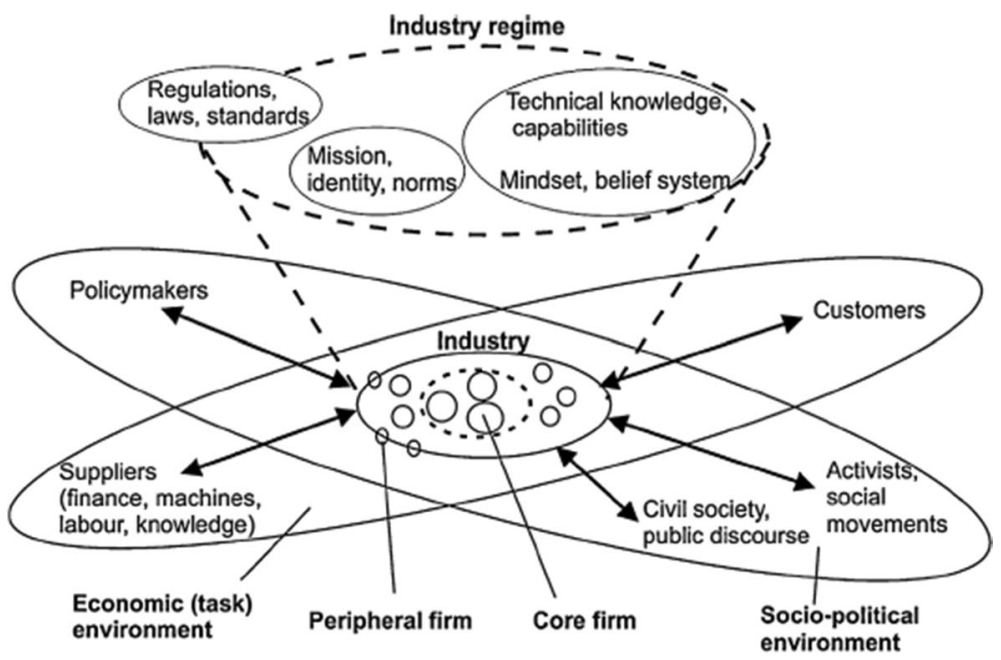

Fig. 1 Triple embeddedness framework by Geels (2014), p. 266 
aspect for cooperation and innovation (Czernek-Marszałek 2020; Jack and Anderson 2002) and thus, exploring "linkages between enterprises [...] rather than the business units themselves" (Strobl and Peters 2013, p.78) is not new to entrepreneurship studies in H\&T. However, research in the context of family entrepreneurs also highlighted several areas of conflict resulting from embeddedness (Li et al. 2013). While some conflicts result from external forces such as customers' demand for sustainability and authenticity (Zanon et al. 2019), others are related to entrepreneurs' embeddedness (Dahl and Sorenson 2012).

Previous literature has extensively used the concept of embeddedness to define the environment of a firm (Granovetter 1985; Halinen and Törnroos 1998). Andersson et al. (2005, p. 523) underlined that the "content of the firm's individual relationships is one important aspect of embeddedness." Thereby, embeddedness also relates to characteristics such as trust (Steier 2001) and improved customer relationships (Zanon et al. 2019). In this context, previous research highlighted several advantages of strong regional ties, such as it ensures more straightforward and cheaper entering into cooperation by securing trust and incorporating social values (Czernek 2014). Also, Boschma and Martin (2010) highlight the role of social embeddedness, resulting from trust through "friendship, kinship and experience through repeated interaction" (2010, p. 122). In summary, already Granovetter (1985) implied the bidirectional relationship between economic outcomes and embeddedness in a social context and thereby also indicated that embeddedness helps to reduce transaction costs within networks. However, Uzzi (1997) and Czernek (2014) highlighted the dark sides of embeddedness such as the necessity to balance between under- and overembedded ties, difficulties in gaining access for external entrepreneurs and the strong influence of family dysfunctions.

Summarizing these elements for regional EE, family firms in rural regions developed a unique entrepreneurial culture because of their strong spatial and social embeddedness in regional contexts (Dahl and Sorenson 2012; Kallmuenzer and Peters 2017; Korsgaard et al. 2015). This especially holds for family firms in H\&T, where entrepreneurship activities primarily address opportunities in close regional proximity (Pikkemaat et al. 2019; Strobl and Peters, 2013). Thus, exploring the role of family firms' embeddedness in regional EE can be expected to enable a better understanding of how this embeddedness drives value creation in regional EE.

\section{Research design}

This paper uses an exploratory case study approach since previous literature highlighted the benefits of building on concrete case knowledge when phenomena are complex and unexplored (Flyvberg 2011). Qualitative research embeds the subject of study within the social context and allows us to understand actors, in our case family entrepreneurs in a broader and deeper context (Creswell 2009) while matching emerging observational with existing theoretical patterns (Sinkovics 2018).

To further specify our theoretical perspective on embeddedness in EE we particularly focus on family businesses because on a regional level in Austria, family firms constitute up to 88 percent of all companies, are responsible for almost 
two-third of employment and generate 57\% of sales (WKO 2018). For gathering the data, we focused on the entrepreneurial landscape in Serfaus (Tyrol, Austria), which is a rural region dominated by family firms and defined by a long-grown history in the H\&T industry. The reasons for choosing this region are manifold: H\&T is a vibrant component of the economy and the region accounts for an above average share of business start-ups (9.4\% in Tyrol, compared to $6.1 \%$ in Austria) and provides 55,000 jobs (Werbung 2018). From 2017 to 2018, the region accounted for 1.2 million overnight stays and represented a successful example of entrepreneurship in a rural setting (Werbung 2018). The strong position of the region as a major player for skiing in the winter season and as a family-friendly and adventurous sports destination in the summer contributes to the strong demand for the region (Serfaus-FissLadis 2020). This development was mostly due to substantial international increases in tourism demand, which led to the creation of 6,900 beds in various categories (Statistics Austria 2020). However, simultaneously, entrepreneurs in H\&T fail more often (responsible for $24 \%$ of insolvencies in the larger metropolitan area) leaving behind the largest share of liabilities (10 million out of 47.4 million Euros in 2018) (Land Tirol 2020). The bottom line is that the H\&T industry is constantly on the move, revenues are constantly rising and, contrary to all expectations, it is proving to be crisis-resistant, at least in the case study region. Thus, family firms in Serfaus show a very entrepreneurial culture in the past years, while most businesses are still family-owned and operated. Recently, also a start-up and research center for the development of outdoor clothing and textiles (AlpineProoflpolychrome-lab) was established (Research Center Snow, Ski and Alpine Sports 2018; Serfaus-Fiss-Ladis 2020). Thus, this region forms an ideal context to investigate entrepreneurship and the role of embeddedness for regional EE.

\subsection{Sample}

We interviewed 20 family entrepreneurs from different generations and across ten hospitality businesses in the rural region of Serfaus (Tyrol, Austria). In the semistructured interviews, family entrepreneurs were selected based on information oriented selection (Flyvberg 2011) and asked about the history of their business and their vision and strategy. Since we were interested in their entrepreneurial perceptions, we also asked them about their understanding of entrepreneurship in terms of their ecosystem. Lastly, we asked in more detail about the factors and elements, which influence their entrepreneurial activity, such as family matters, quality of life and financial performance. Table 2 highlights key characteristics of the interviewees' organizations. The recorded interviews lasted for 50 to $70 \mathrm{~min}$ each and were transcribed and analyzed by using MAXQDA (MAXQDA 2020).

\subsection{Data analysis}

To analyze the data, we followed the pattern-matching approach aiming to "externalize implicit mental models and assumptions as much as possible" (p. 468) and operationalized it by using template analysis, which follows the pattern-matching 
Table 2 Sample overview

\begin{tabular}{lclll}
\hline No. beds & No. employees & $\begin{array}{l}\text { Generation in } \\
\text { control }\end{array}$ & Interviewees & IDs \\
\hline 381 & 190 & 2 nd & Interviewee Father \& Daughter & C1, R1-2 \\
486 & 130 & 1 st & Interviewee Father \& Son & C2, R1-2 \\
350 & 100 & 1 st & Interviewee Father \& Son & C3, R1-2 \\
160 & 40 & 2 nd & Interviewee Father \& Son & C4, R1-2 \\
100 & 36 & 1 st & Interviewee Father \& Son & C5, R1-2 \\
70 & 11 & 2 nd & Interviewee Mother \& Daughter & C6, R1-2 \\
45 & 7 & 1 st & Interviewee Mother \& Daughter & C7, R1-2 \\
28 & 3 & $2 n d$ & Interviewee Father \& Daughter-in-law & C8, R1-2 \\
40 & 1 & 1 st & Interviewee Mother \& Son & C9, R1-2 \\
25 & 1 & 1 st & Interviewee Mother \& Daughter & C10, R1-2 \\
\hline
\end{tabular}

logic as specified by Sinkovics (2018, p. 474). Template analysis (King et al. 2019) allows for a structure and flexible approach to combine deductive and inductive codes to identify overarching themes within the data. We constructed the initial template with "entrepreneurship" and "embeddedness" topics as level one deductive codes, applied it to a set of the interviews and then revised until it "captures as full a picture of the analyst's understanding as possible" (King et al. 2019, p. 219). Based on the inductive coding process with a subset of transcripts to complete the template, we developed additional level one codes such as "perceptions of growth" and refined level two codes such as e.g., "entrepreneurship out of commitment", "the role of strenghtening informal ties" or "family entrepreneurs' interpretation of success". To link existing theoretical insights on embeddedness with our empirical observations, we created a matrix accounting for horizontal, vertical and spatial patterns of embeddedness. This process was supported by the qualitative data analysis software "MAXQDA," which allows managing the codes and further quantitative/ qualitative analysis (MAXQDA 2020). The flexible pattern matching approach also promotes the formulation of propositions (see discussion section) to further explore phenomena and build theory (Sinkovics 2018, p. 475). The data was coded independently by two researchers and discussed in multiple rounds within the research team to ensure intra- and intercoder reliability. In summary, the final template featured three main categories along horizontal, vertical and spatial patterns: themes discussing entrepreneurship in the region, the embeddedness of the firm within the region and family and finally, codes describing growth patterns and issues of family firms (for an example of the coding template see Table 3). 


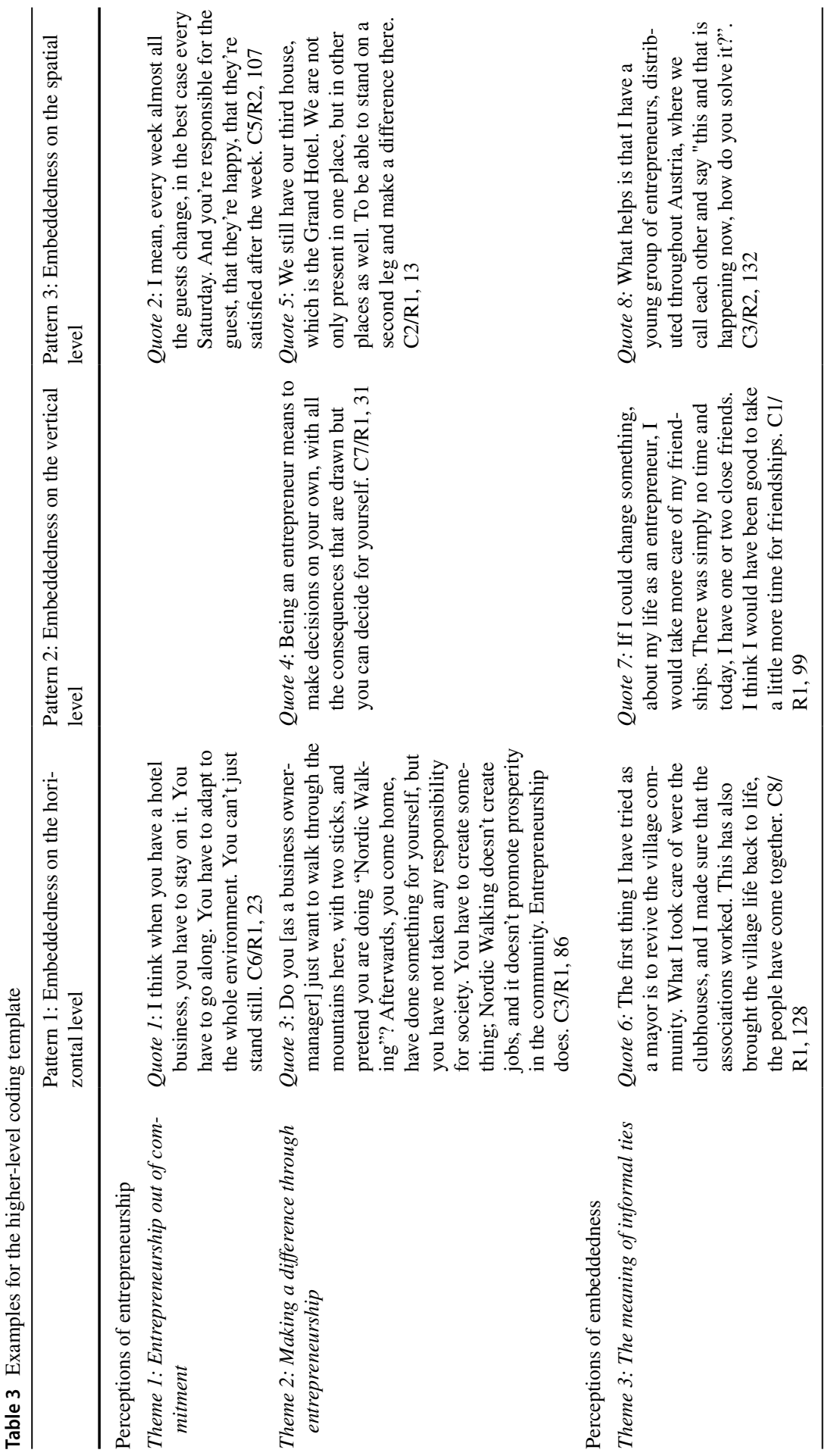




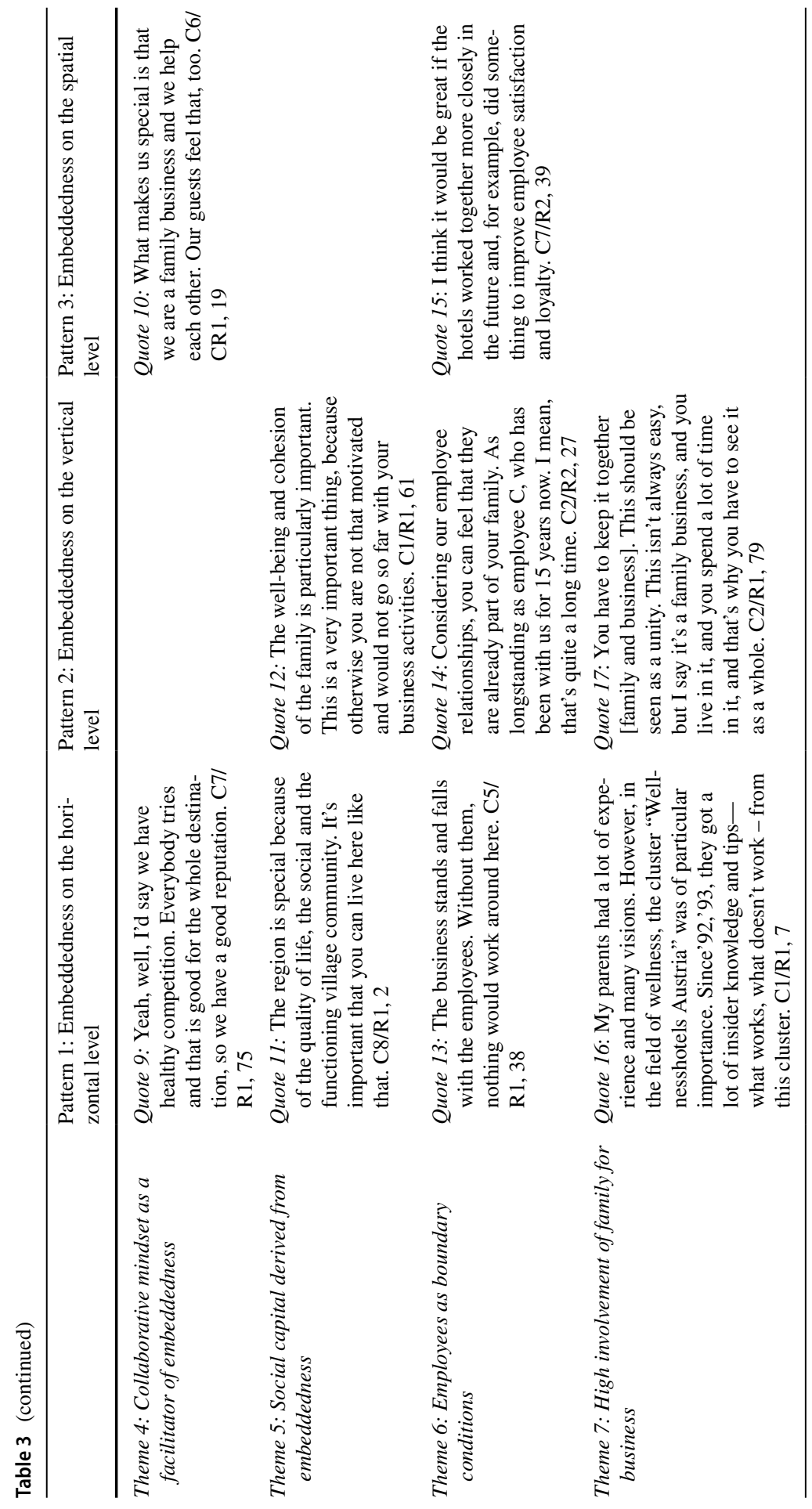




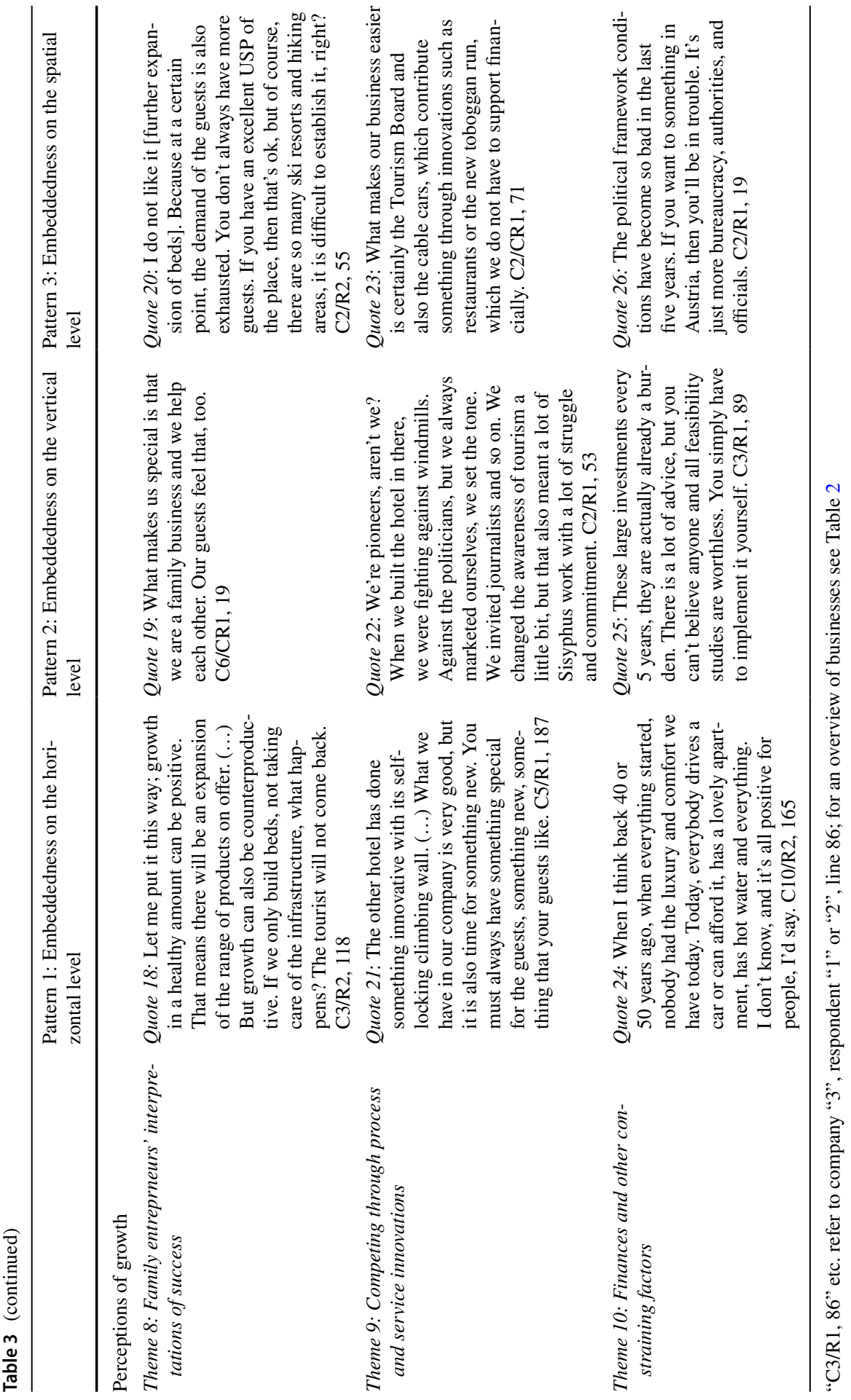




\section{Results}

Previous literature highlighted the distinctive characteristics regional EEs (de Villiers Scheepers et al. 2018; Prencipe et al. 2020). Thus, in our investigations we primarily focus on family entrepreneurs' perceptions of embeddedness, as we showed that there exists a demand for more research on the social factors that shape EEs (Brown and Mason 2017). Three themes became evident when analyzing the data following the coding template (Table 3). Embeddedness indeed showed to be the central theme, but also firm-related themes, such as growth or entrepreneurial activities were intensely discussed.

\subsection{Horizontal dimensions of embeddedness}

Family entrepreneurs relate their understanding of entrepreneurship to the local circumstances in the case study region. Many of them want to be "creators" or "designers" of their local environment. When being asked about their understanding of entrepreneurship and quality of life, an interviewee made a particularly detailed description (see Table 3, quote 3).

This statement shows that family entrepreneurs want to have an impact on the local community through their entrepreneurial activity. In this context, also the potential recognition for achievements by the community was an important topic. Overall, family entrepreneurs showed a strong commitment towards continuing business operations in the future. For this reason, family entrepreneurs emphasized the importance of being embedded within the local community. This was mostly associated with informal ties to local sport clubs, heritage clubs and aimed to strengthen informal ties to other entrepreneurs and intermediaries relevant for business but also private life. Thereby, associations performed an important task in developing social capital. This became particularly visible in the following statement:

There's a kind of solidarity in the local associations. For example, there are music and farmers' associations. There is a strong cohesion. It's also an opportunity for networking. C8/R1, 118 .

Another interviewee referred to the social capital derived from family entrepreneurs' embeddedness in the region. For many entrepreneurs, the region was of particular importance and many family entrepreneurs could not imagine doing business in another region (see Table 3, quote 11).

Quality of life also links to another controversial topic of entrepreneurship in H\&T. Due to the high service orientation, the industry is time- and resourceintensive, leaving little time for non-business-related activities in the high season. Thus, creating and maintaining support systems outside of business operations emerged as a distinctive feature to ensure a vibrant regional EE.

Honestly, peasant women are important. Through them, people get together and through that, I got to know many, many people, also from the larger district area. C9/R1, 205. 
While embeddedness within local structures was of high importance for our interviewees, we also observed that some family entrepreneurs developed strong ties within the broader industry. For example, interviewees highlighted the support services of various organizations, mentors, and consultants for realizing their entrepreneurial activities. One interviewee explained that a critical incident in the formation and development of the hotel was to become a member of a business cluster focused on wellness (see Table 3, Quote 16).

While networks with entrepreneurs from the same industry were perceived important, family entrepreneurs often looked for support from outside of their regional EE. Next to legal requirements, interviewees were also dissatisfied about their networks and relationships with traditional providers of finances.

Banks used to believe in you and trusted you and said: "Okay, you'll get the money from us." Today you don't get anything anymore, and if you don't have many securities, then you don't get anything. That's how it is. Back in the days, they were much more open and trustworthy, and they almost appreciated any business operations. C2/R1, 25.

This also indicates that family entrepreneurs still mostly rely on traditional capital sources such as either bank loans or also capital from family counterparts. However, interviewees reported that this can also lead to issues when it comes to succession and family members withdraw their ownership positions. Many family entrepreneurs, despite their strong growth and success in recent years, reported feeling to struggle from a financial perspective.

Another issue that emerged in the interviews was employee attraction and retention, which was perceived as an ongoing and restricting issue for entrepreneurial activity, since local communities are becoming less willing to work on H\&T and the supply of skilled external labor is limited. Nevertheless, many interviewees reported having long term employees, which are well integrated within the organization and also the family structure. As a result, strong bonds between family members and long-term employees have developed (see Table 3, quote 14).

Interviewees also emphasized to benefit from the knowledge that they have acquired and accumulated over the time of their operations. In this context, it became apparent that family entrepreneurs have become highly skilled when it comes to handle customers' preferences. Only one interviewee criticized the authenticity of services, while most owner-managers emphasized the need to "listen to customers" and some perceived their role to "charm the snake". An interviewee explained:

The entrepreneur always has to ear the guest, right? You also have to develop a certain feeling for it, right? And you have to listen to that. C2/R1, 51.

This idea of feeling and sensing the host-guest relationship is developed from childhood on and is based on continuous involvement in business activities. Thus, these early childhood experiences shape many successors mindsets and later also skillsets. For example, many successors are used to time constraints because of business obligations and spending a lot of time in the business. However, this also has 
several consequences for the involved families, which we are going to explore in the following part.

\subsection{Vertical dimensions of embeddedness}

Since topics related to family involvement emerged as an essential in the literature review, we also explored this aspect in greater detail. Our interviewees emphasized that family involvement is an important aspect that influences their business decisions. Usually, family entrepreneurs highlighted that decisions are coordinated with family members, most of the time with spouses and also children if old enough. This became visible in the following quote:

If it is a family business, it is vital that decisions are always made by the family. You don't decide on your own. We always tell our children that they don't have to do it [getting involved in the business] because of us, their parents. C6/ R1.

However, interviewees also mentioned that the high degree of family involvement in the organization is also leading to tensions. Many interviewees mentioned issues to separate private life from business life and referred to a lack of time for family and friends, resulting from demanding business obligations and working hours (see Table 3, quote 7). This also confirms the importance that family entrepreneurs assign to strengthening informal ties. Not surprisingly, many interviewees reported that entrepreneurship in H\&T requires high levels of commitment on a personal level in order to sustain the business. Not surprisingly, family entrepreneurs were concerned of "keeping the family together" (see Table 3, quote 17). However, we observed that young entrepreneurs often showed a distinct entrepreneurial culture compared to previous generations. Their understanding of entrepreneurship was less traditional compared to the founding generation whose intention was to grow despite all difficulties and the feeling to "fight against windmills" (see Table 3, quote 22). Frequently, young entrepreneurs perceived growth as "nothing to desire." Instead of growth, they emphasized the importance of managing innovation in times of increased demand for service and quality. Many of these young entrepreneurs portrayed a managerial leadership style with less aggressive behaviour towards competitiors. In this context, interviewees were aware that their business environment is constantly changing, and thus, emphasizing the need for innovations. Most innovations that were reported in the interviews referred to new product or service developments or process innovation instead of business model innovations (see Table 3 , quote 21).

This also underlines the fact that family entrepreneurs were mostly thinking of incremental innovations rather than changing their existing business models. Nevertheless, the family image was perceived as an important aspect, helping to communicate the importance of helping each other internally but also to communicate this to customers (see Table 3, quote 19). 


\subsection{Spatial dimensions of embeddedness}

Since our interviewees were all located within the same ecosystem, which is community-oriented, our interviewees stated that cooperation with other entrepreneurs is an essential feature and strength, helping them to deliver their products and services. Cooperations include, for example, meetings and discussions but also relate to more tangible partnerships. One interviewee made a particularly interesting description of such a partnership (see Table 3, quote 10).

In the interviews, an important theme was that business partners are located within the ecosystem. This is not surprising, since we already indicated that family entrepreneurs prefer to develop strong ties with their environment (see Table 3, quotes 11). In addition, our interviewees emphasized the importance of formal and informal relationships to connect with other entrepreneurs outside of local networks. For this reason, interviewees reported to use different mechanisms such as memberships is business associations but also informal networks to exchange knowledge about business operations. While earlier generations are stronger rooted in more structured and local forms of meetings, young entrepreneurs also use more direct means of communication (see Table 3, quote 8).

Additionally, young entrepreneurs are trying to diversify the spatial range of their network. While the comment above referred to colleagues and friends "distributed throughout Austria," other entrepreneurs have started to extend their business operations beyond the borders of the regional RE.

We still have our third house, which is the Grand Hotel. We are not only present in one place, but in other places as well. To be able to stand on a second leg and make a difference there. C2/R1, 13.

Besides, some interviewees also thought of working together to improve the visibility and attractivity of employment in the hospitality industry across the borders of the region (see Table 3, quote 15). Another topic that emerged on a larger spatial scale was that the political arena, in charge of regulations and laws is currently not perceived supportive. Due to the many requirements of legal nature, many family entrepreneurs were concerned that this hampers future development by restricting, e.g., access to finances (see Table 3, quote 26).

Lastly, most interviewees reported that they do not support further expansion of bed capacity since they are concerned about enough demand from the global ecosystem (see Table 3, quote 20). However, to diversify their business models, none of the interviewees reported engaging in activities that are not related to the core of their industry. 


\section{Discussion}

The regional EE perspective offers a novel approach to explore the role of family entrepreneurs in contributing to sustainable development through value creation in regional EE (Filser et al. 2019). In this context, many studies discussed factors and conditions enabling entrepreneurial activity (Stam 2015). Isenberg (2010) highlighted the role of technology, money, talent, a critical mass of ventures, and a culture that encourages collaborative innovation and tolerates failure for EEs. However, our results portray a very distinct entrepreneurial culture, which is characterized by less aggressive growth and innovation. The findings underline managed growth and lifestyle patterns, which are driven by family dynamics and family entrepreneurs' social ties in the hospitality and tourism context (Neumeyer et al. 2019). Thus, the findings support that regional EE as communities of interrelated actors show distinctive dynamics and peculiarities than more global and high growth ecosystems. Thus, extending existing measures to the scope of regional EE seems important (cf. Liguori et al. 2019). Mapping existing knowledge against our empirical findings (Sinkovics 2018), results in the following proposition:

Proposition 1 Regional EEs require spatially based and family-centered entrepreneurship measures to capture the context of entrepreneurial vibrancy.

We focused on a regional $\mathrm{EE}$ that has a long-standing tradition as hub for H\&T activities, showing high network density and connectivity. Specifically, we focused on the previously often overlooked but critical social context of entrepreneurship in a regional EEs (Brown and Mason 2017; Neumeyer et al. 2019). Since the individual level of entrepreneurs is perceived as key for knowledge exploitation and entrepreneurial activity (Table 1) in regional EEs (de Villiers Scheepers et al. 2018; Stam 2015), we explored the role of embeddedness as a spatial and social factor for entrepreneurial activity. Stam (2015) showed that entrepreneurial activity not only depends on the presence of framework conditions such as sufficient demand but also on systemic conditions such as networks and examples of successful entrepreneurship. Our findings underline that successful entrepreneurship in regional EEs goes beyond the presence of these elements by highlighting the value of interpersonal foundations for bridging ecosystem elements. Thus, considering family entrepreneurs' embeddedness and enriching it with findings on the logic of family businesses (Kallmuenzer et al. 2017), can be a central element for understanding regional EEs with many family firms. Therefore, our second proposition is:

Proposition 2 Unravelling the important role of family entrepreneurs' embeddedness is paramount to understand how it regulates the design of regional EE.

The early work on embeddedness (Granovetter 1985; Gulati 1998; Uzzi 1997) and evolutionary economics (Geels 2014) allowed us to distill the key features of embeddedness, which affect family entrepreneurship in regional EEs (Stam 


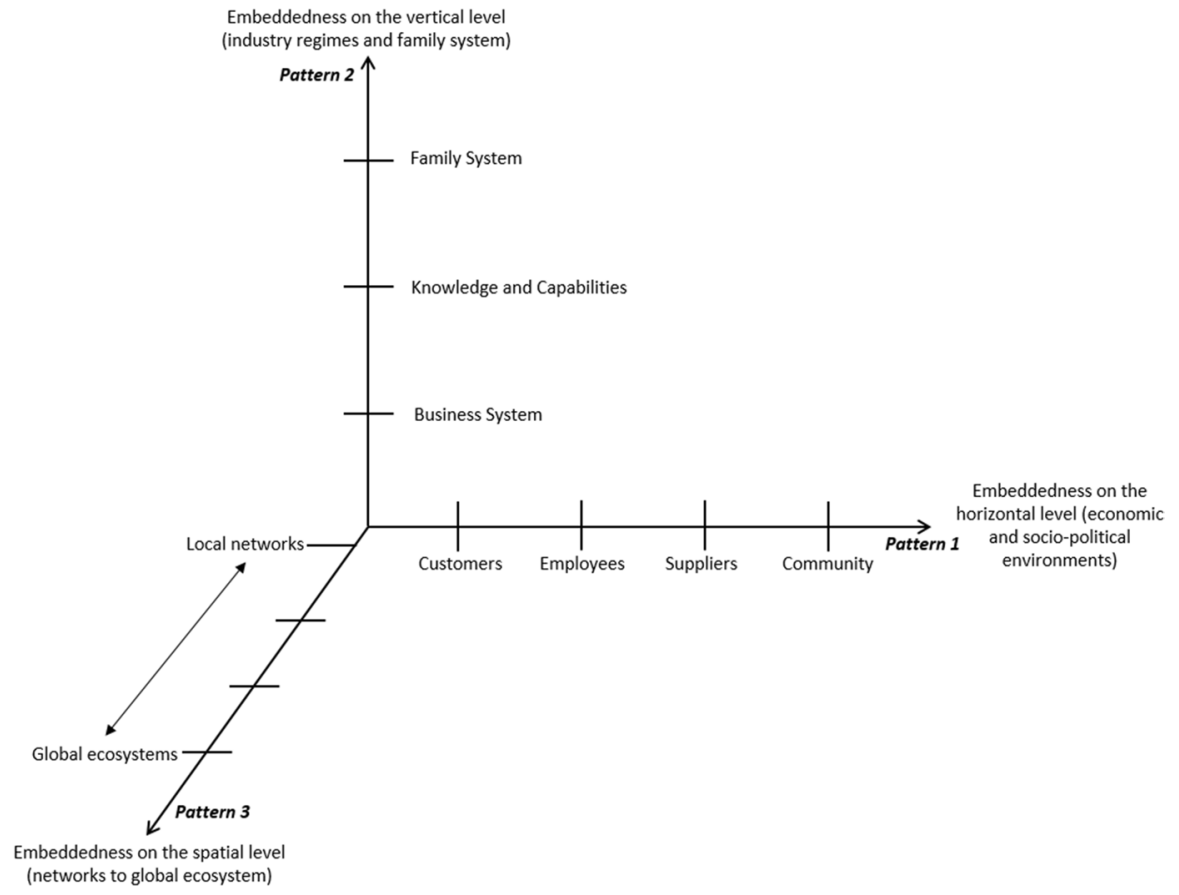

Fig. 2 EEE (Entrepreneurial Ecosystem Embeddedness) Framework

2015). Our findings confirm that embeddedness is central for entrepreneurial activity (Czernek 2014; Dahl and Sorenson 2012; Korsgaard et al. 2015) and thereby we strengthen its position as a social context factor for regional EEs (Brown and Mason 2017; de Villiers Scheepers et al. 2018). Based on our conceptual considerations and the empirical results, we attempt to summarize results in the three-dimensional Entrepreneurial Ecosystem Embeddedness (EEE) Framework (Fig. 2).

Horizontal embeddedness (Fig. 2, pattern 1) refers to the importance that family entrepreneurs assigned to local and regional ties for entrepreneurial activity. These findings support previous scholars (Czernek 2014; Jack and Anderson 2002), showing the importance of social embeddedness for cooperation and firm performance. In general, high levels of social capital are perceived as beneficial for entrepreneurs since it allows exploiting the knowledge accumulated in these relationships (Weiler and Hinz 2019). However, the observed relationships are of highly informal nature, characterized by many strong ties (Granovetter 1973). This leads to a situation where in contrast to Korsgaard et al. (2015), family entrepreneurs look for external sources of knowledge (e.g., consultants, cluster) instead of "exhaust(ing) the localized resource base before seeking out non-local resources" (Korsgaard et al. 2015, p. 574). This also links to the concept of relational embeddedness, showing that strongly tied actors "tend to emulate each 
other's behavior" (Gulati 1998, p. 296), which can lead to decision-making constraints (Li et al. 2013).

Another way of describing this local network is by using the allegory of "you just know each other," which characterizes the high degree of proximity and informal relationships that family entrepreneurs have developed in this region. There is little evidence that family entrepreneurs are professionally engaging in networking activities but instead use a laissez-faire approach to manage their networks. This leads to a situation where family entrepreneurs are meeting on a regular basis for informal activities but the missing network orchestration limits its potential benefits for improving entrepreneurial activity or collaborative innovation. We have focused on factors within the sphere of influence of family entrepreneurs, but it has been shown that exogenous uncertainty can also play a major role for network constellations in ecosystems (Lingens et al. 2020). Incubators offer a solution to reduce uncertainty and improve orchestration. Although Isenberg (2010) doubted the effectiveness of incubators for venture creation, we support their importance, e.g. managed by a DMO, in the case of a regional EE for improving orchestration and dealing with strong embeddedness and exogenous uncertainty. This also aligns with van Rijnsoever (2020) calling for incubators to guide the process between "meeting" and "mating" in networks.

The lack of collaborative innovation also leads to a situation where family entrepreneurs become stuck (Ward 1997) and focus on incremental innovations such as service and product improvements (e.g., improvements in wellness areas or new recreational facilities) (Pikkemaat et al. 2019). Some family entrepreneurs achieve innovations by involving external actors, but the majority of firms become "exploiters" or "rigid firms," which deny every form of development (Clauss et al. 2020). This also links to previous EE literature highlighting that mature regions with high levels of embeddedness may suffer from potential "lock-in" effects (Boschma and Martin 2010). At first sight, this seems to only emerge from family entrepreneurs' engagement in H\&T, but the interviews showed that this also results from family entrepreneurs' immobility. We also found that young entrepreneurs have different mobility and leadership characteristics compared to the founding generation and offer new career opportunities for non-family managers (Stam 2013) and themselves by improving wellbeing through a more managerial leadership style. In terms of embeddedness, regional EE benefit as breaking up too much vertical embeddedness leads to new opportunities for innovation and venture creation. However, in contrast to the initial idea of Isenberg (2010), there is still little toleration for failure and change within the region despite young entrepreneurs' strive for change. On this argument, we formulate the following proposition:

Proposition 3 Regional EE are more likely to suffer from high degrees of centralized embeddedness which can hinder aggregate value creation.

We also indicated the importance of vertical embeddedness (Fig. 2, pattern 2) and three mechanisms could be distinguished: Vertical embeddedness includes family entrepreneurs' perceptions of entrepreneurship, which are more about managing 
existing structures (Neumeyer et al. 2019) and less about innovative high-growth oriented entrepreneurs in the Schumpeterian tradition (Schumpeter 1934). Nevertheless, due to the long-term engagement, family entrepreneurs have accumulated enough knowledge to excel in operational excellence and customer intimacy by developing a strong service culture (Scott et al. 2017). However, this also requires a high degree of family involvement in business operations, putting pressure on owner families and leading to intensive working hours. Thereby, family entrepreneurs need to balance between business and family-related objectives (Berrone et al. 2012; Gómez-Mejía et al. 2007). This is also supported by our findings on vertical embeddedness, where entrepreneurs are simultaneously concerned about the degree of family involvement but unable to sustain operations without the support of the family. In line with previous literature, we observed conflicts emerging from increasing international competition and limited innovation behavior, limited availability of capital and willingness to invest, insecurities about succession and related inflexibility and resistance to change (Ward 1997). The fourth proposition is:

Proposition 4 Supporting regional EE development requires strategies to unbundle and better manage the link between work, leisure and family.

Family entrepreneurs noted the importance of intensifying their knowledge exchange with other regions and extending their business operations to other areas. Therefore, the EEE framework also includes a spatial dimension (Fig. 2, pattern 3 ), which fits well with previous literature, highlighting that EE can develop various spatial dimensions, ranging from local to global (Stam 2015). In this context, the most local levels were understood as spatial agglomerations at the village and industry level (Roundy 2019), which culminated into cluster approaches (Scott et al. 2019) and later regional innovation systems (Asheim et al. 2011; Hjalager 2010). Nevertheless, understanding regions as territories of successful entrepreneurship (Stam 2015) implies several benefits, such as putting agency of individual entrepreneurs to the core (Brown and Mason 2017). First, this underlines the fact that spatial embeddedness as a factor of entrepreneurship should not be viewed in isolation from the broader social context of, e.g., horizontal and vertical embeddedness. Second, spatial embeddedness also frames an answer to low levels of innovations in family firms by highlighting the need to pay special attention to their relationships to universities and specialized schools (Miller and Acs 2017). Besides, spatial embeddedness highlights the potential of accessing new ideas and knowledge pools by entering global ecosystems, which help to translate core competencies such as customer intimacy and operational excellence to other business areas such as the provision of, e.g., coworking spaces or workplaces for home office. Our final proposition is:

Proposition 5 Extending the spatial reach of family entrepreneurs supports the vibrancy of regional EE by accessing new sources for knowledge and securing synergies. 
In summary, regional EE in H\&T are strongly place-based but require stronger links to other industries to overcome issues of embryonic ecosystems, which are known to "have cohesive internal interactions and are quite self-contained but lack a depth of connections and diversity of entrepreneurial actors" (Brown and Mason 2017, p.24).

\section{Conclusion}

This paper explored how family entrepreneurs' embeddedness as a social fabric drives regional EE development. Identifying patterns of embeddedness through a qualitative approach helped us show how family entrepreneurs' embeddedness drives regional EE development. Based on the findings, we derived the EEE framework (Fig. 2), which matches existing knowledge on horizontal and vertical embeddedness and extends it with a novel spatial perspective. The EEE framework highlights the role of (1) family entrepreneurs' horizontal embeddedness in the economic and socio-political environment, their (2) vertical embeddedness in industry regimes, in particular the family, and their 3) spatial embeddedness in the region for value creation.

We add to EE literature by highlighting the need to better manage embeddedness on a three-dimensional level across the ecosystem. We showed that strong ties in the business context (e.g., partnerships with local entrepreneurs who are active in the same industry) can limit innovations and therefore entrepreneurial vibrancy. A more fruitful approach is engaging in mediated activities such as startup hubs, accelerator programs or mediated incubators (van Rijnsoever 2020) to foster innovations (Feld 2012). Our discussion also addressed the role of family dynamics, which are driven by socio-emotional wealth considerations for vertical embeddedness. Thus, family entrepreneurs should reconsider the degree of involvement of family members (e.g., executive and non-executive) in business operations since we showed that family entrepreneurs need to balance between business and family-related outcomes. Lastly, the EEE framework requires family entrepreneurs to manage their spatial embeddedness on the continuum from local to global EE. This includes but is not limited to establishing ties within the inner-industry, with the broader industry but also across industries. Managing spatial embeddedness helps family entrepreneurs to exploit and generate knowledge, ultimately leading to innovation.

The contribution of this paper is threefold. First, we responded to previous calls to broaden the academic research horizon beyond established entrepreneurship theories (Ferreira et al. 2019). Thus, we supplement the existing literature on local and regional EE (Cao and Shi 2020) by highlighting the role of embeddedness to better understand the social factors that shape entrepreneurial activity (Brown and Mason 2017). Second, we locate the embeddedness perspective (Geels 2014; Granovetter 1985) within the EE approach (de Villiers Scheepers et al. 2018; Stam 2015). This also offers new insights into factors that influence family entrepreneurs' activities and shows that vibrant EE not only exist on a global level but also on a more regional level with the requirement to manage embeddedness to sustain a vibrant ecosystem. 
Third, we add to existing family firm literature by highlighting the specific value of regional EE research in contrast to previous notions of clusters or regional innovation systems in tourism (Hjalager 2010) and beyond (Asheim et al. 2011; Rondé and Hussler 2005; Stam 2013).

This study also shows several managerial implications. Since the findings highlighted the strong local and regional roots of the interviewees, it will be of particular importance for them to expand their networks and seek strategic partnerships with external actors (Strobl and Kronenberg 2016), who can deliver new knowledge, e.g., in the field of technology (Beliaeva et al. 2020; Eller et al. 2020). Among other actors, this study also examined the role of employees for entrepreneurial activity; entrepreneurs should also consider the aspirations of entrepreneurial employees (Stam 2013) since this can also improve performance (Hellmann 2007). In most businesses, family owners however show a strong tendency to favor family members in the management of the organization (Barnett and Kellermanns 2006). Lastly, in several occasions high levels of embeddedness can result in adverse effects for future entrepreneurial activity. Kellermanns et al. (2012) already highlighted the dark sides of socio-emotional wealth and our results additionally encourage that too strong embeddedness decreases performance (Kallmuenzer et al. 2018). Embeddedness helps to gather regional competitive advantages to increase market barriers for new market entrants through innovation; this holds especially for family-firm dominated regions (Block and Spiegel 2013). However, regional innovation systems need both internal and external stimuli to further foster innovations. Therefore, regions need to carefully examine their options to link their system to global players and ecosystems (see Fig. 2) in the sense of acting as an open regional innovation system (Belussi et al. 2010). Also, Li et al. (2013) showed that strong relational ties could result in decision-making constraints since these ties also oblige entrepreneurs to other stakeholders.

Future research needs to discuss the local-global continuum of EE and pose the question of whether and how these EE systems share elements such as formal institutions, culture, finances, or talent (Stam 2015). Additionally, future research is necessary to uncover the embeddedness-performance relationship and provide robust and feasible indicators for regional EE (see proposition 1). Furthermore, industry characteristics and exogenous uncertainty arising from demand shocks or crises may strongly influence the outcomes of such a study (Lingens et al. 2020). Thus, a life cycle perspective regarding the composition of embeddedness and regional EE should be considered for future research.

As common, this paper also shows several limitations. First, ecosystems are constantly changing and previous research often focused on entities with successful examples of entrepreneurship (Spigel and Harrison 2018), neglecting nonentrepreneurial businesses and those that went out of business over time. Second, a qualitative research design cannot confirm causal relationships (Flyvberg 2011), but rather targets to provide a thick description of a phenomenon and develop theory, such as the EEE framework. In detail, we can only propose but do not know whether embeddedness represents a sufficient or necessary condition for the formation of EE (Stam 2015). Lastly, we only interviewed entrepreneurs from the 
hospitality industry and did not focus on other entrepreneurs within the region. Therefore, it would be interesting to trace the potential effects of knowledge spillover from the investigated industry to other sectors.

Funding Open Access funding provided by University of Innsbruck and Medical University of Innsbruck. Not applicable.

Availability of data and materials Data will be made available on request.

\section{Compliance with ethical standards}

Conflict of interest There is no conflict of interest with any financial organization or among authors regarding the content of the manuscript.

Consent to participate All interviewees have given their consent to participate in this study.

Consent for publication All authors have given their consent to submit this study.

Ethics approval This study follows the advice of the University of Innsbruck regarding research ethics.

Open Access This article is licensed under a Creative Commons Attribution 4.0 International License, which permits use, sharing, adaptation, distribution and reproduction in any medium or format, as long as you give appropriate credit to the original author(s) and the source, provide a link to the Creative Commons licence, and indicate if changes were made. The images or other third party material in this article are included in the article's Creative Commons licence, unless indicated otherwise in a credit line to the material. If material is not included in the article's Creative Commons licence and your intended use is not permitted by statutory regulation or exceeds the permitted use, you will need to obtain permission directly from the copyright holder. To view a copy of this licence, visit http://creativecommons.org/licen ses/by/4.0/.

\section{References}

Adner R (2017) Ecosystem as structure: an actionable construct for strategy. J Manag 43:39-58. https:// doi.org/10.1177/01492063166784

Alvedalen J, Boschma R (2017) A critical review of entrepreneurial ecosystems research: towards a future research agenda. Eur Plan Stud 25:887-903. https://doi.org/10.1080/09654313.2017.1299694

Andersson U, Björkman I, Forsgren M (2005) Managing subsidiary knowledge creation: the effect of control mechanisms on subsidiary local embeddedness. Int Bus Rev 14:521-538. https://doi. org/10.1016/j.ibusrev.2005.07.001

Asheim BT, Smith HL, Oughton C (2011) Regional innovation systems: theory, empirics and policy. Reg Stud 45:875-891. https://doi.org/10.1080/00343404.2011.596701

Astrachan JH, Shanker MC (2003) Family businesses' contribution to the U.S. economy: a closer look. Fam Bus Rev 16:211-219. https://doi.org/10.1177/08944865030160030601

Ateljevic I, Doorne S (2000) "Staying within the fence": lifestyle entrepreneurship in tourism. J Sustain Tour 8:378-392. https://doi.org/10.1080/09669580008667374

Audretsch DB, Cunningham JA, Kuratko DF, Lehmann EE, Menter M (2019) Entrepreneurial ecosystems: economic, technological, and societal impacts. J Technol Transf 44:313-325. https://doi. org/10.1007/s10961-018-9690-4

Bachinger M, Kofler I, Pechlaner H (2020) Sustainable instead of high-growth? Entrepreneurial ecosystems in tourism. J Hosp Manag Tour 44:238-242. https://doi.org/10.1016/j.jhtm.2020.07.001

Baggio R (2011) Collaboration and cooperation in a tourism destination: a network science approach. Curr Issue Tour 14:183-189. https://doi.org/10.1080/13683500.2010.531118 
Baggio R, Cooper C (2010) Knowledge transfer in a tourism destination: the effects of a network structure. Serv Ind J 30:1757-1771. https://doi.org/10.1080/02642060903580649

Barnett T, Kellermanns FW (2006) Are we family and are we treated as family: nonfamily employees' perceptions of justice in the family firm. Entrep Theor Pract 30:837-854. https://doi.org/10.111 1/j.1540-6520.2006.00155.x

Baù M, Chirico F, Pittino D, Backman M, Klaesson J (2019) Roots to grow: family firms and local embeddedness in rural and urban contexts. Entrep Theor Pract 43:360-385. https://doi.org/10.1177/10422 58718796089

Beliaeva T, Ferasso M, Kraus S, Damke EJ (2020) Dynamics of digital entrepreneurship and the innovation ecosystem. Int J Entrep Behav Res 26:266-284. https://doi.org/10.1108/IJEBR-06-2019-0397

Belussi F, Sammarra A, Sedita SR (2010) Learning at the boundaries in an "open regional innovation system": a focus on firms' innovation strategies in the Emilia Romagna life science industry. Res Policy 39:710-721. https://doi.org/10.1016/j.respol.2010.01.014

Beritelli P, Bieger T, Laesser C (2014) The new frontiers of destination management. J Travel Res 53:403-417. https://doi.org/10.1177/0047287513506298

Berrone P, Cruz C, Gomez-Mejia LR (2012) Socioemotional wealth in family firms. Fam Bus Rev 25:258-279. https://doi.org/10.1177/0894486511435355

Block JH, Spiegel F (2013) Family firm density and regional innovation output: an exploratory analysis. J Fam Bus Strat 4:270-280. https://doi.org/10.1016/j.jfbs.2013.10.003

Boes K, Buhalis D, Inversini A (2016) Smart tourism destinations: ecosystems for tourism destination competitiveness. Int J Tour Cities 2:108-124. https://doi.org/10.1108/IJTC-12-2015-0032

Boesen M, Sundbo D, Sundbo J (2017) Local food and tourism: an entrepreneurial network approach. Scand J Hosp Tour 17:76-91. https://doi.org/10.1080/15022250.2016.1218629

Boschma R, Martin R (2010) The handbook of evolutionary economic geography. Edward Elgar, Cheltenham

Bouncken RB, Kraus S, Roig-Tierno N (2019) Knowledge- and innovation-based business models for future growth: digitalized business models and portfolio considerations. Rev Manag Sci. https:// doi.org/10.1007/s11846-019-00366-Z

Brown R, Mason C (2017) Looking inside the spiky bits: a critical review and conceptualisation of entrepreneurial ecosystems. Small Bus Econ 49:11-30. https://doi.org/10.1007/s11187-017-9865-7

Cao Z, Shi X (2020) A systematic literature review of entrepreneurial ecosystems in advanced and emerging economies. Small Bus Econ 51:501. https://doi.org/10.1007/s11187-020-00326-y

Clauss T, Bouncken RB, Laudien S, Kraus S (2020) Business model reconfiguration and innovation in SMEs: a mixed-method analysis from the electronics industry. Int J Innov Manag. https://doi. org/10.1142/S1363919620500152

Cohen B (2006) Sustainable valley entrepreneurial ecosystems. Bus Strat Environ 15:1-14. https://doi. org/10.1002/bse.428

Creswell JW (2009) Qualitative inquiry and research design: choosing among five approaches, 2nd edn. Sage, Thousand Oaks

Cunha C, Kastenholz E, Carneiro MJ (2020) Entrepreneurs in rural tourism: do lifestyle motivations contribute to management practices that enhance sustainable entrepreneurial ecosystems? J Hosp Manag Tour 44:215-226. https://doi.org/10.1016/j.jhtm.2020.06.007

Cunningham JA, Menter M, Wirsching K (2019) Entrepreneurial ecosystem governance: a principal investigator-centered governance framework. Small Bus Econ 52:545-562. https://doi.org/10.1007/ s11187-017-9959-2

Czernek K (2014) The role of social embeddedness in tourist region cooperation. Eur J Tour Hosp Recreat 5:61-81

Czernek-Marszałek K (2020) Social embeddedness and its benefits for cooperation in a tourism destination. J Destin Mark Manag 15:1-17. https://doi.org/10.1016/j.jdmm.2019.100401

Dahl MS, Sorenson O (2012) Home sweet home: entrepreneurs' location choices and the performance of their ventures. Manag Sci 58:1059-1071. https://doi.org/10.1287/mnsc.1110.1476

de Villiers Scheepers MJ, Mealy E, Clements M, Lawrence A (2018) Regional entrepreneurship ecosystems support: South East Queensland as case study. In: O’Connor A, Stam E, Sussan F, Audretsch DB (eds) Entrepreneurial ecosystems: place-based transformations and transitions. Springer, Cham, pp 101-130

Duran P, Kammerlander N, van Essen M, Zellweger T (2016) Doing more with less: Innovation input and output in family firms. Acad Manag J 59:1224-1264. https://doi.org/10.5465/amj.2014.0424 
Eichelberger S, Peters M, Pikkemaat B, Chan C-S (2020) Entrepreneurial ecosystems in smart cities for tourism development: from stakeholder perceptions to regional tourism policy implications. J Hosp Manag Tour. https://doi.org/10.1016/j.jhtm.2020.06.011

Eller R, Alford P, Kallmünzer A, Peters M (2020) Antecedents, consequences, and challenges of small and medium-sized enterprise digitalization. J Bus Res 112:119-127. https://doi.org/10.1016/j.jbusr es.2020.03.004

Feld B (2012) Startup communities: building an entrepreneurial ecosystem in your city. Wiley, New York

Ferreira JJM, Fernandes CI, Kraus S (2019) Entrepreneurship research: mapping intellectual structures and research trends. Rev Manag Sci 13:181-205. https://doi.org/10.1007/s11846-017-0242-3

Filser M, Kraus S, Roig-Tierno N, Kailer N, Fischer U (2019) Entrepreneurship as catalyst for sustainable development: opening the black box. Sustainability 11:4503. https://doi.org/10.3390/su11164503

Flores A, Pereira E, Graça H (2017) Entrepreneurial ecosystems. In: Scott N, de Martino M, van Niekerk $\mathrm{M}$ (eds) Knowledge transfer to and within tourism: academic, industry and government bridges, vol 8, 1st edn. Emerald Publishing, Bingley, pp 97-111

Flyvberg B (2011) Case study. In: Denzin NK, Lincoln Y (eds) The SAGE handbook of qualitative research, 4th edn. Thousand Oaks, Los Angeles, pp 301-316

Gamble JR, Clinton E, Díaz-Moriana V (2020) Broadening the business model construct: exploring how family-owned SMEs co-create value with external stakeholders. J Bus Res. https://doi. org/10.1016/j.jbusres.2020.03.034

Geels FW (2014) Reconceptualising the co-evolution of firms-in-industries and their environments: developing an inter-disciplinary Triple Embeddedness Framework. Res Policy 43:261-277. https:// doi.org/10.1016/j.respol.2013.10.006

Getz D, Carlsen J (2005) Family business in tourism. Ann Tour Res 32:237-258. https://doi. org/10.1016/j.annals.2004.07.006

Gómez-Mejía LR, Haynes KT, Núñez-Nickel M, Jacobson KJL, Moyano-Fuentes J (2007) Socioemotional wealth and business risks in family-controlled firms: evidence from Spanish olive oil mills. Admin Sci Q 52:106-137. https://doi.org/10.2189/asqu.52.1.106

Granovetter MS (1973) The strength of weak ties. Am J Sociol 78:1360-1380

Granovetter MS (1985) Economic action and social structure: the problem of embeddedness. Am J Sociol 91:481-510

Gulati R (1998) Alliances and networks. Strat Manag J 19:293-317. https://doi.org/10.1002/(SICI)10970266(199804)19:4\%3c293:AID-SMJ982\%3e3.0.CO;2-M

Hakala H, O'Shea G, Farny S, Luoto S (2020) Re-storying the business, innovation and entrepreneurial ecosystem concepts: the model-narrative review method. Int J Manag Rev 22:10-32. https://doi. org/10.1111/ijmr.12212

Halinen A, Törnroos J-A (1998) The role of embeddedness in the evolution of business networks. Scand J Manage 14:187-205. https://doi.org/10.1016/S0956-5221(98)80009-2

Hellmann T (2007) When do employees become entrepreneurs? Manag Sci 53:919-933. https://doi. org/10.1287/mnsc. 1060.0648

Hess M (2004) 'Spatial' relationships?: Towards a reconceptualization of embeddedness. Prog Hum Geogr 28:165-186. https://doi.org/10.1191/0309132504ph479oa

Higuchi Y, Yamanaka Y (2017) Knowledge sharing between academic researchers and tourism practitioners: a Japanese study of the practical value of embeddedness, trust and co-creation. J Sustain Tour 25:1456-1473. https://doi.org/10.1080/09669582.2017.1288733

Hjalager A-M (2010) Regional innovation systems: the case of angling tourism. Tour Geogr 12:192-216. https://doi.org/10.1080/14616681003725201

Isenberg DJ (2010) How to start an entrepreneurial revolution. Harv Bus Rev 88:1-11

Jack SL, Anderson AR (2002) The effects of embeddedness on the entrepreneurial process. J Bus Ventur 17:467-487. https://doi.org/10.1016/S0883-9026(01)00076-3

Kallmuenzer A, Peters M (2017) Exploring entrepreneurial orientation in family firms: the relevance of social embeddedness in competition. Int J Entrep Small Bus 30:191. https://doi.org/10.1504/IJESB .2017 .081436

Kallmuenzer A, Peters M (2018) Entrepreneurial behaviour, firm size and financial performance: the case of rural tourism family firms. Tour Recreat Res 43:2-14. https://doi.org/10.1080/02508 281.2017.1357782

Kallmuenzer A, Nikolakis W, Peters M, Zanon J (2017) Trade-offs between dimensions of sustainability: exploratory evidence from family firms in rural tourism regions. J Sustain Tour 23:1-18. https:// doi.org/10.1080/09669582.2017.1374962 
Kallmuenzer A, Strobl A, Peters M (2018) Tweaking the entrepreneurial orientation-performance relationship in family firms: the effect of control mechanisms and family-related goals. Rev Manag Sci 12:855-883. https://doi.org/10.1007/s11846-017-0231-6

Kang Q, Li H, Cheng Y, Kraus S (2019) Entrepreneurial ecosystems: analysing the status quo. Knowl Manag Res Pract 52:1-13. https://doi.org/10.1080/14778238.2019.1701964

Kellermanns FW, Eddleston KA, Zellweger TM (2012) Extending the socioemotional wealth perspective: a look at the dark side. Entrep Theor Pract 36:1175-1182. https://doi.org/10.111 1/j.1540-6520.2012.00544.x

King N, Horrocks C, Brooks JM (2019) Interviews in qualitative research, 2nd edn. Sage, Los Angeles

Kline C, Hao H, Alderman D, Kleckley JW, Gray S (2014) A spatial analysis of tourism, entrepreneurship and the entrepreneurial ecosystem in North Carolina, USA. Tour Plann Dev 11:305-316. https ://doi.org/10.1080/21568316.2014.890127

Korsgaard S, Ferguson R, Gaddefors J (2015) The best of both worlds: how rural entrepreneurs use placial embeddedness and strategic networks to create opportunities. Entrep Region Dev 27:574-598. https://doi.org/10.1080/08985626.2015.1085100

Krueger N (2012) Bridging town and gown: best practice?: an essay on growing the local entrepreneurial ecosystem. Int J Bus Global 9:347-358

Land Tirol (2020) Statistisches Handbuch Bundesland Tirol 2019. https://www.tirol.gv.at/fileadmin/ themen/statistik-budget/statistik/downloads/Statistisches_Handbuch_2019.pdf. Accessed 18 Aug 2020

Le Breton-Miller I, Miller D (2016) Family firms and practices of sustainability: a contingency view. J Fam Bus Strat 7:26-33. https://doi.org/10.1016/j.jfbs.2015.09.001

Li Y, Wang X, Huang L, Bai X (2013) How does entrepreneurs' social capital hinder new business development: a relational embeddedness perspective. J Bus Res 66:2418-2424. https://doi.org/10.1016/j. jbusres.2013.05.029

Liguori E, Bendickson J, Solomon S, McDowell WC (2019) Development of a multi-dimensional measure for assessing entrepreneurial ecosystems. Entrep Region Dev 31:7-21. https://doi. org/10.1080/08985626.2018.1537144

Lingens B, Miehé L, Gassmann O (2020) The ecosystem blueprint: how firms shape the design of an ecosystem according to the surrounding conditions. L Rang Plann. https://doi.org/10.1016/j. lrp.2020.102043

MacKenzie N (2016) Family businesses and entrepreneurship ecosystems. https://eernetwork.org/index .php/2016/01/20/family-businesses-and-entrepreneurship-ecosystems. Accessed 23 Nov 2020

MAXQDA (2020) All-in-one qualitative and mixed methods data analysis tool. https://www.maxqd a.com/. Accessed 14 Jan 2020

Miller D, Le Breton-Miller I (2006) Family governance and firm performance: agency, stewardship, and capabilities. Fam Bus Rev 19:73-87. https://doi.org/10.1111/j.1741-6248.2006.00063.x

Miller DJ, Acs ZJ (2017) The campus as entrepreneurial ecosystem: the University of Chicago. Small Bus Econ 49:75-95. https://doi.org/10.1007/s11187-017-9868-4

Milwood PA, Maxwell A (2020) A boundary objects view of entrepreneurial ecosystems in tourism. J Hosp Manag Tour 44:243-252. https://doi.org/10.1016/j.jhtm.2020.06.008

Motoyama Y, Konczal J, Bell-Masterson J, Morelix A (2014) Think locally, act locally: building a robust entrepreneurial ecosystem. http://ssrn.com/abstract=2425675. Accessed 26 Mar 2020

Narduzzo A, Volo S (2018) Tourism innovation: when interdependencies matter. Curr Issue Tour 21:735741. https://doi.org/10.1080/13683500.2016.1214111

Neumeyer X, Santos SC, Morris MH (2019) Who is left out: exploring social boundaries in entrepreneurial ecosystems. J Technol Transf 44:462-484. https://doi.org/10.1007/s10961-018-9694-0

Nicotra M, Romano M, Del Giudice M, Schillaci CE (2018) The causal relation between entrepreneurial ecosystem and productive entrepreneurship: a measurement framework. J Technol Transf 43:640673. https://doi.org/10.1007/s10961-017-9628-2

Pechlaner H, Thees H, Eckert C, Zacher D (2018) Vom Entrepreneurship Ecosystems zur Entrepreneurial Destination: Perspektiven einer Standortentwicklung am Beispiel der Freizeitszene München. In: Bruhn M, Hadwich K (eds) Service business development. Springer Fachmedien Wiesbaden, Wiesbaden, pp 477-507

Pikkemaat B, Peters M, Bichler BF (2019) Innovation research in tourism: research streams and actions for the future. J Hosp Manag Tour 41:184-196. https://doi.org/10.1016/j.jhtm.2019.10.007 
Prencipe A, Corsi C, Rodríguez-Gulías MJ, Fernández-López S, Rodeiro-Pazos D (2020) Influence of the regional entrepreneurial ecosystem and its knowledge spillovers in developing successful university spin-offs. Socio Econ Plan Sci. https://doi.org/10.1016/j.seps.2020.100814

Ratten V (2020) Entrepreneurial ecosystems: future research trends. Thund Int Bus Rev. https://doi. org/10.1002/tie.22163

Research Center Snow, Ski and Alpine Sports (2018) Project competence center textiles. http://sport 1.uibk.ac.at/fzssa/index.php?page=kompz.html. Accessed 3 Dec 2018

Rondé P, Hussler C (2005) Innovation in regions: what does really matter? Res Policy 34:1150-1172. https://doi.org/10.1016/j.respol.2005.03.011

Roundy PT (2019) "It takes a village" to support entrepreneurship: intersecting economic and community dynamics in small town entrepreneurial ecosystems. Int Entrep Manag J 15:1443-1475. https://doi. org/10.1007/s11365-018-0537-0

Rutten R, Boekema F (2007) Regional social capital: embeddedness, innovation networks and regional economic development. Technol Forecast Soc Change 74:1834-1846. https://doi.org/10.1016/j. techfore.2007.05.012

Schumpeter JA (1934) The theory of economic development. Harvard University Press, Cambridge

Scott N, Martino M de, van Niekerk M (eds) (2017) Knowledge transfer to and within tourism: academic, industry and government bridges, 1 st edn. Bridging Tourism Theory and Practice, vol 8. Emerald Publishing, Bingley

Scott S, Hughes M, Kraus S (2019) Developing relationships in innovation clusters. Entrep Region Dev 31:22-45. https://doi.org/10.1080/08985626.2018.1537145

Serfaus-Fiss-Ladis (2020) Destination Serfaus-Fiss-Ladis. https://www.serfaus-fiss-ladis.at/en/winter. Accessed 13 Sept 2018

Sinkovics N (2018) Pattern matching in qualitative analysis. In: Cassell C, Cunliffe A, Grandy G (eds) The SAGE handbook of qualitative business and management research. SAGE Publications Ltd, London, pp 468-484

Spigel B, Harrison R (2018) Toward a process theory of entrepreneurial ecosystems. Strateg Entrep J 12:151-168. https://doi.org/10.1002/sej.1268

Stam E (2013) Knowledge and entrepreneurial employees: a country-level analysis. Small Bus Econ 41:887-898. https://doi.org/10.1007/s11187-013-9511-y

Stam E (2015) Entrepreneurial ecosystems and regional policy: a sympathetic critique. Eur Plan Stud 23:1759-1769. https://doi.org/10.1080/09654313.2015.1061484

Stam E, Spigel B (2017) Entrepreneurial ecosystems. In: Blackburn R, de Clercq D, Heinonen J, Wang Z (eds) The SAGE handbook of small business and entrepreneurship, 1st edn. SAGE Publications, London, pp 407-422

Stam E, van de Ven A (2019) Entrepreneurial ecosystem elements. Small Bus Econ. https://doi. org/10.1007/s11187-019-00270-6

Stangler D, Bell-Masterson J (2015) Measuring an entrepreneurial ecosystem. Kauffman Foundation Research Series on City, Metro, and Regional Entrepreneurship, Kansas City

Statistics Austria (2020) The information manager. https://www.statistik.at/web_en/statistics/index.html. Accessed 4 Feb 2020

Steier L (2001) Family firms, plural forms of governance, and the evolving role of trust. Fam Bus Rev 14:353-367. https://doi.org/10.1111/j.1741-6248.2001.00353.x

Strobl A (2014) What ties resources to entrepreneurs? - activating social capital. Int J Entrep Ventur 6:140. https://doi.org/10.1504/IJEV.2014.062749

Strobl A, Kronenberg C (2016) Entrepreneurial networks across the business life cycle: the case of Alpine hospitality entrepreneurs. Int J Contemp Hosp Manag 28:1177-1203. https://doi.org/10.1108/ IJCHM-03-2014-0147

Strobl A, Peters M (2013) Entrepreneurial reputation in destination networks. Ann Tour Res 40:59-82. https://doi.org/10.1016/j.annals.2012.08.005

Thees H, Zacher D, Eckert C (2020) Work, life and leisure in an urban ecosystem: co-creating Munich as an entrepreneurial destination. J Hosp Manag Tour 44:171-183. https://doi.org/10.1016/j. jhtm.2020.06.010

Theodoraki C, Messeghem K, Rice MP (2018) A social capital approach to the development of sustainable entrepreneurial ecosystems: an explorative study. Small Bus Econ 51:153-170. https://doi. org/10.1007/s11187-017-9924-0 
Thompson TA, Purdy JM, Ventresca MJ (2018) How entrepreneurial ecosystems take form: Evidence from social impact initiatives in Seattle. Strateg Entrep J 12:96-116. https://doi.org/10.1002/ sej. 1285

Tirol Werbung (2018) Der Tiroler Tourismus: Zahlen, Daten und Fakten 2017. https://www.tirolwerbu ng.at/wp-content/uploads/2018/04/tiroler-tourismus-daten-und-fakten-2017.pdf-daten-und-fakte n-2017.pdf\&usg=AOvVaw15gEkGC6NDhBp5FMi4ilch. Accessed 30 Aug 2019

Trunfio M, Campana S (2019) Drivers and emerging innovations in knowledge-based destinations: towards a research agenda. J Destin Mark Manag. https://doi.org/10.1016/j.jdmm.2019.100370

Uzzi B (1997) Social structure and competition in interfirm networks: the paradox of embeddedness. Adm Sci Q 42:35. https://doi.org/10.2307/2393808

van Rijnsoever FJ (2020) Meeting, mating, and intermediating: how incubators can overcome weak network problems in entrepreneurial ecosystems. Res Policy 49:1-15. https://doi.org/10.1016/j.respo 1.2019 .103884

Villegas-Mateos A (2020) Regional entrepreneurial ecosystems in Chile: comparative lessons. J Entrep Emerg Econ. https://doi.org/10.1108/JEEE-11-2019-0168

Ward JL (1997) Growing the family business: Special challenges and best practices. Fam Bus Rev 10:323-337. https://doi.org/10.1111/j.1741-6248.1997.00323.x

Weiler M, Hinz O (2019) Without each other, we have nothing: a state-of-the-art analysis on how to operationalize social capital. Rev Manag Sci 13:1003-1035. https://doi.org/10.1007/s1184 6-018-0280-5

WKO (2018) WKO Analyse: Familienunternehmen in Österreich. https://news.wko.at/news/oesterreic h/2018_15_Familienunternehmen.pdf. Accessed 3 Sept 2020

Zanon J, Scholl-Grissemann U, Kallmuenzer A, Kleinhansl N, Peters M (2019) How promoting a family firm image affects customer perception in the age of social media. J Fam Bus Strat 10:28-37. https ://doi.org/10.1016/j.jfbs.2019.01.007

Zehrer A, Raich F, Siller H, Tschiderer F (2014) Leadership networks in destinations. Tour Rev 69:59_ 73. https://doi.org/10.1108/TR-06-2013-0037

Publisher's Note Springer Nature remains neutral with regard to jurisdictional claims in published maps and institutional affiliations.

\title{
Affiliations
}

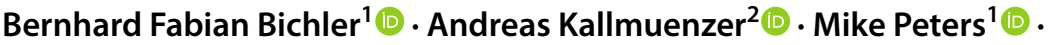 Tanja Petry ${ }^{1}\left[\right.$. Thomas Clauss ${ }^{3}[$}

\author{
Andreas Kallmuenzer \\ kallmuenzera@excelia-group.com \\ Mike Peters \\ mike.peters@uibk.ac.at \\ Tanja Petry \\ Tanja.petry@uibk.ac.at \\ Thomas Clauss \\ Thomas-clauss@uni-wh.de
}

1 Department of Strategic Management, Marketing and Tourism / SME and Tourism, University of Innsbruck, Karl-Schönherr-Strasse 3, 6020 Innsbruck, Austria

2 Department of Strategy, Excelia Business School - CERIIM, 102 Rue de Coureilles, 17000 La Rochelle, France

3 Witten Institute for Family Business, University Witten/Herdecke, Alfred-Herrhausen-Str. 50, 58448 Witten, Germany 